\title{
Family Medicine in the Research Revolution
}

\author{
Richard C. Wender, MD
}

National Institutes of Health (NIH) funding has contributed to improvements in the health of the nation, but the pace of progress, particularly in the war on cancer, has been frustratingly slow. Departments of family medicine receive less NIH funding than all other specialties. Although numerous factors contribute to low family medicine funding levels, persistent undervaluing of primary care plays a paramount role.

Fueled by the harsh reality that our nation's health is unconscionably poor, we are entering a new era in our nation's research enterprise, a virtual research revolution. The 3 components of this revolution are the NIH roadmap, personalized medicine, and the Clinical and Translational Science Awards. Each of these elements will contribute to a growing emphasis on translational research. Translational research demands formation of innovative structures in academic health centers (AHCs) to enable them to address questions of vital relevance to improving public health. Service research, funded by the Agency for Healthcare Research and Quality, the Centers for Disease Control and Prevention, and foundations, defines a new approach to research with high potential to improve the health of communities.

To be a part of the research revolution, departments must rely on senior researchers to secure funding and provide mentorship for junior investigators. Junior investigators must relentlessly pursue answers to questions of direct relevance to improving health. Finally, department chairs have the obligation to identify research mentors, find ways to fund research gaps, and create a culture of scholarship and investigation. Advocating for AHCs to commit to improving the health of the regions they serve can have a substantial impact on the types of questions that centers choose to study and, ultimately, on the health of the communities they serve. (J Am Board Fam Med 2010;23:431-439.)

An analysis of more than 50 years of research funding by the National Institutes of Health $(\mathrm{NIH})$ suggests that it has helped to avert up to $\$ 1.35$ million deaths per year from cardiovascular disease, stroke, cancer, and diabetes. ${ }^{1}$ Although one can reasonably conclude that the NIH has had a dramatic positive impact on public health, this contention has been challenged by some analysts who argue that the speed of progress is far less than could have been accomplished with wiser investment of research funding. How should the success of our research enterprise be judged? The ultimate measure of all aspects of our health care enterprise must be the extent to which our nation's health

From the Department of Family and Community Medicine, Thomas Jefferson University, Jefferson Medical College, Philadelphia, PA.

Funding: none.

Conflict of interest: none declared.

Corresponding author: Richard C. Wender, MD, Department of Family and Community Medicine, Thomas Jefferson University/Jefferson Medical College, 1015 Walnut Street, Suite 401, Philadelphia, PA 19107 (E-mail: richard.wender@jefferson.edu). actually improves. During the past 30 years, deaths from heart disease have declined significantly, with some drop in the rate of deaths from cerebrovascular disease as well. In addition, fewer deaths are occurring from common infections diseases, such as influenza and pneumonia (Figure 1). We have much to celebrate.

However, numerous examinations of our progress in the war on cancer create doubt about the effectiveness of our research investment. During the past 40 years, Americans have spent around $\$ 400$ billion to combat cancer. We are beginning to win this long and difficult war. We have seen significant reductions in age-adjusted mortality form lung, prostate, and colon cancers in men as well as breast, cervix, and colon cancers in women (Figures 2 and 3). But several examinations of our progress against cancer have found reasons for concern. "When you break down the 'Big 4' cancers by stages, long-term survival for advanced cancer has barely budged since the 1970s." ${ }^{4}$ Why has progress not been more rapid? 
Figure 1. Change in US death rates (age-adjusted to the 2000 US standard population) from 1991 to 2006. Reprinted from reference 2 .

Rate Per 100,000

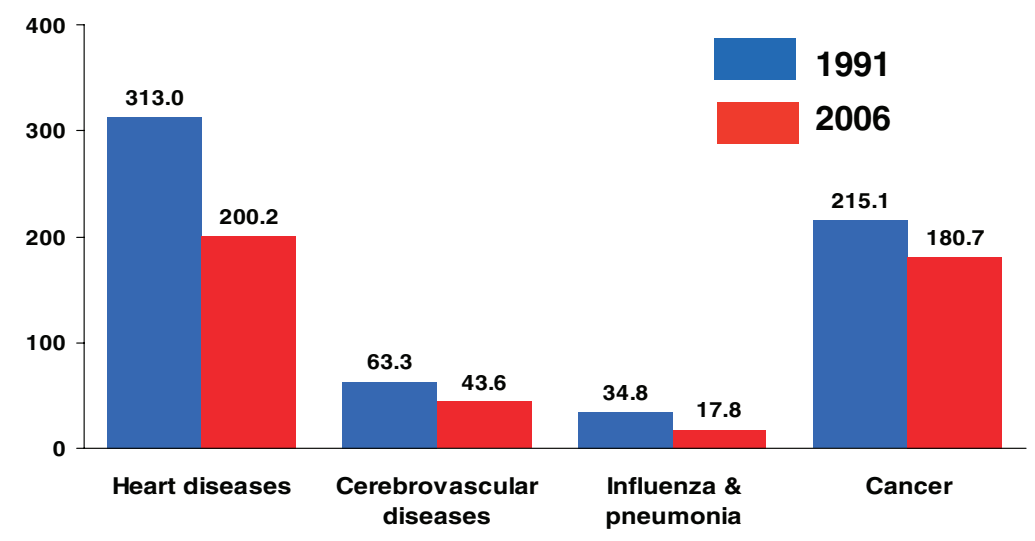

Although manifold factors are relevant, perhaps misguided investment in basic research plays some role. As Clifton Leaf wrote, "Through 2004, the cancer community has published 150,855 experimental studies...on mice.”4

In 1999, the American Cancer Society (ACS) set a goal for the nation to reduce age-adjusted cancer mortality by $50 \%$ by the year 2015 , compared with the 1991 mortality peak. In 2006, the ACS conducted a midpoint analysis of the campaign to achieve this 2015 mortality reduction goal. The ACS concluded that, "Many more deaths can be averted by concerted action to control tobacco [use] and obesity, by redoubling efforts on mammography and colorectal cancer screening, and by enacting policies to close gaps in access to cancer detection and treatment services." This analysis supports a re-examination of our investment in research.

Regardless of our satisfaction or dissatisfaction with the speed of research progress, the need to keep forging ahead is unchallenged. The NIH, the largest source of research funding in the world, must remain the driving engine of progress. The flattening of the NIH research budget from 2004 through 2008 created severe distress in the research

Figure 2. Cancer death rates (age-adjusted to the 2000 US standard population) among men in the United States, 1930 to 2005. Reprinted from Cancer Statistics, 2009, Vol. 59, No. 4, 2009, pp 225-49. ${ }^{3}$ Copyright 2009 American Cancer Society. This material is reproduced with permission of Wiley-Liss, Inc., a subsidiary of John Wiley \& Sons, Inc.

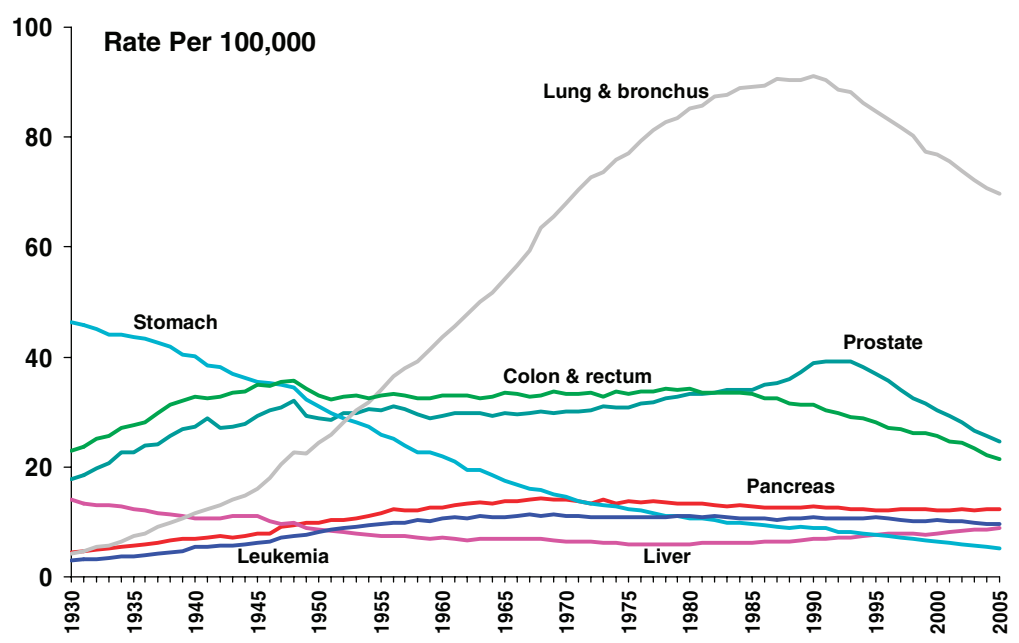


Figure 3. Cancer death rates (age-adjusted to the 2000 US standard population) among women in the United States, 1930 to 2005. Reprinted from Cancer Statistics, 2009, Vol. 59, No. 4, 2009, pp 225-49. ${ }^{3}$ Copyright 2009 American Cancer Society. This material is reproduced with permission of Wiley-Liss, Inc., a subsidiary of John Wiley \& Sons, Inc.

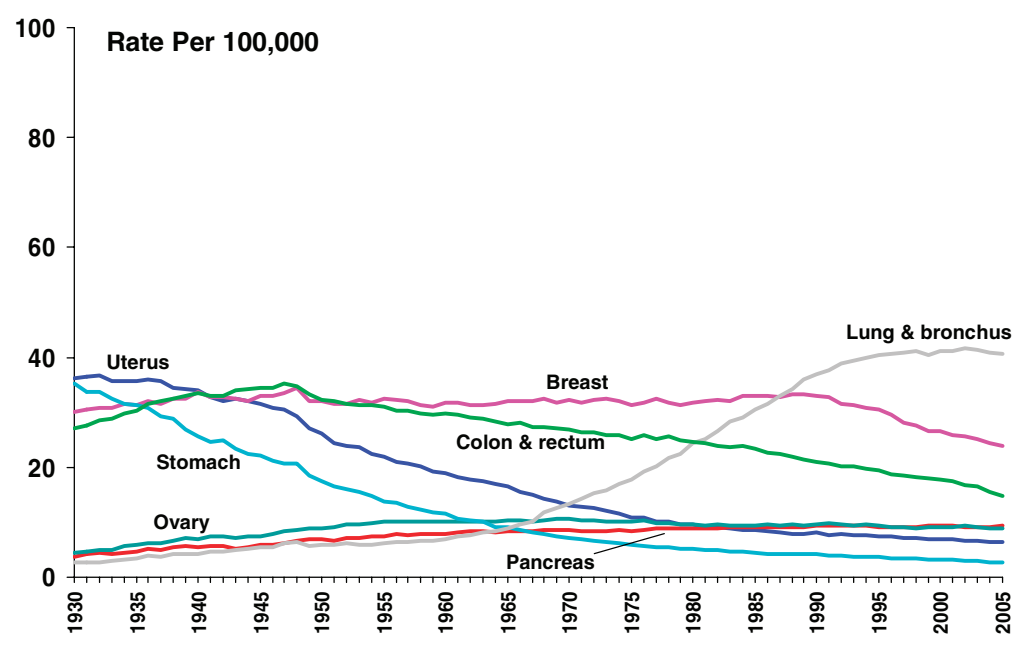

community. Making a living seeking NIH fundingnever an easy goal-became extraordinarily difficult and left many promising young investigators to question their career direction. Figuring out how to navigate the NIH peer review process defines one of the central challenges for most health researchers.

\section{NIH Funding to Departments of Family Medicine}

$\mathrm{NIH}$ funding for principal investigators in departments of family medicine has been particularly hard to come by. As shown in Figure 4, NIH funding to departments of family medicine has lagged far behind funding for every other medical specialty. Although the percent of funding to primary investigators in departments of family medicine did reach an all-time high in 2009, family medicine funding has yet to crack the $1 \%$ line; family medicine has received only a sliver of the NIH pie.

Why has NIH funding for departments of family medicine lagged so far behind funding to other specialties? Although debate about the relative contribution of various factors is reasonable, virtually any analysis of this funding conundrum would

Figure 4. NIH funding. ${ }^{6,7}$
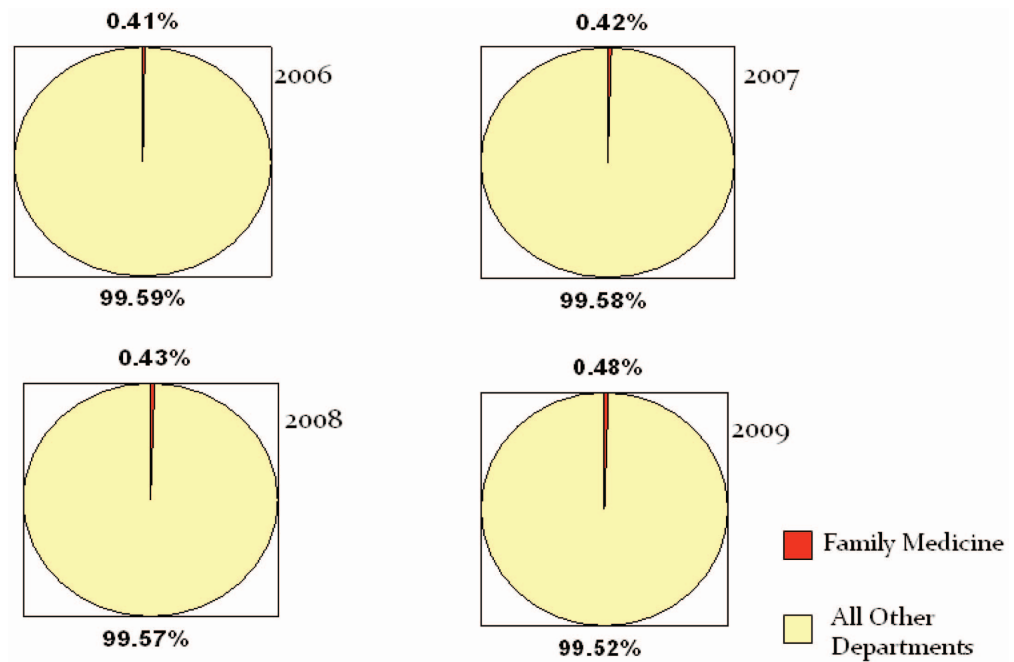
Figure 5. Number of NIH awards: FY 1995 to 2007. Adapted from reference 10.

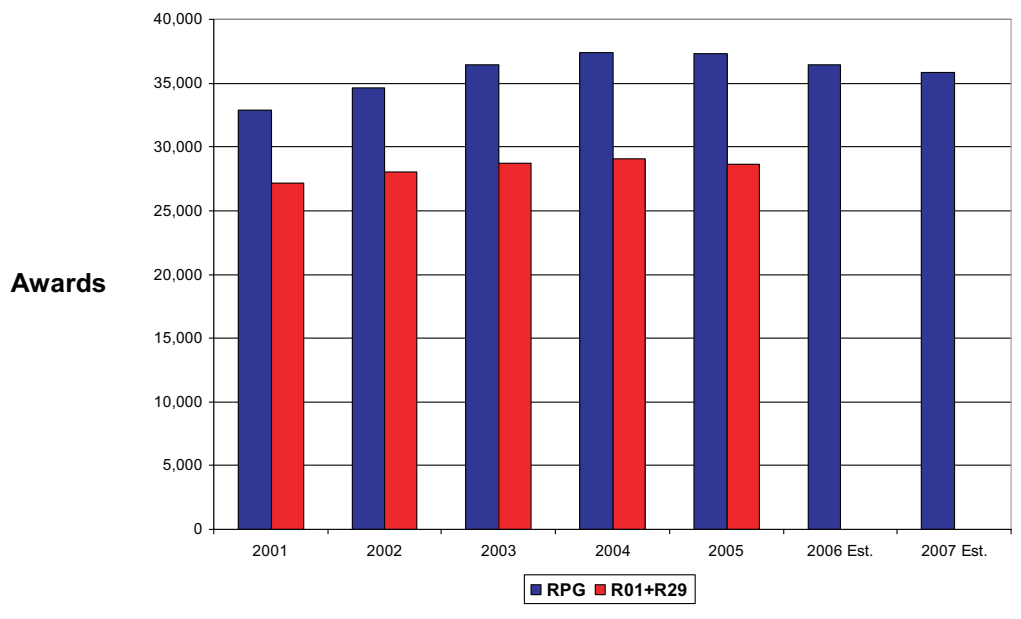

probably include most or all of the items proposed here (they are listed in reverse priority order).

10. Students who are interested in becoming researchers do not choose family medicine. "Only $1.4 \%$ of medical students graduating from $\mathrm{MD} / \mathrm{PhD}$ programs from 2000 to 2006 chose family medicine as their career path-by far the lowest of any specialty." 8

9. Many family medicine academic programs do not conduct research. In 2007, only 44 of 120 departments of family medicine sponsored an NIH principal investigator.

8. Academic leaders in family medicine underestimate what it takes to succeed. Rabinowitz et $\mathrm{al}^{9}$ conducted a detailed analysis of the $2003 \mathrm{NIH}$ awards to departments of family medicine. In that year, only 17 family physicians were serving as principle investigators on return on investment (ROI) grants. The oft-pursued model of the 1-year faculty development fellowship does not adequately prepare faculty members to compete successfully for research funding. ${ }^{9}$

7. More and more investigators are competing for fewer and fewer dollars. Figures 5 and 6 illustrate the decline in the number of NIH awards and the fall in success rates for all competing NIH grants during the first half of this decade. Although stimulus dollars have produced an upsurge in available federal grant dollars, this increase is short-lived. Furthermore, the recent economic downturn has decreased the level of support available through many foundations.

Figure 6. Success rates for all competing NIH grants: FY 1995 to 2005. Adapted from reference 10.

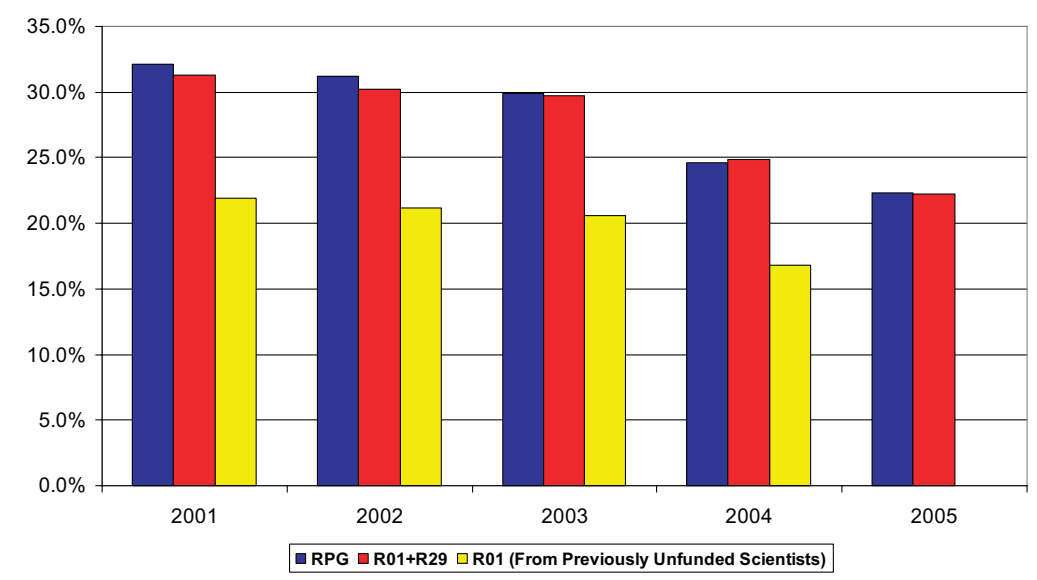


6. We are generalists and proud of it! However, the $\mathrm{NIH}$ is not designed to support generalism. Lucan et al interviewed a series of administrative and research leaders within the NIH. This analysis quoted various $\mathrm{NIH}$ administrators who indicated that the "NIH is "two-thirds basic science' and 'disease-based'... family physicians have 'no natural home for seeking funding." "11

5. Family medicine research mentors are few and far between. Mentored career development awards are an important bridge to becoming an independent investigator, but obtaining such an award requires a skilled mentor with a proven track record. In 2003, the NIH awarded 146 grants to 109 different primary investigators in departments of family medicine. Forty-four of these awards, including $\mathrm{K}$ grants, were to family physicians. ${ }^{9}$ Many departments would not be able to identify a qualified senior family medicine research mentor.

4. Family medicine research infrastructure bas no obvious business model. Although diverting surplus generated through clinical activity to support research development is a logical and appealing approach to research funding, departments of family medicine have no consistent way to generate a clinical surplus.

3. Clinical research is very difficult to do, and population research in the community is particularly challenging. NIH research leaders recognize the inherent difficulty of conducting this type of research. As written in the NIH Roadmap, “... clinical research has become increasingly difficult to do and... the scientific community... must recast its entire system of clinical research." Community-based research requires a long time to carry out, which can result in a delay in publication and a limitation to the total number of publications that emerge from any one project. Furthermore, the costs of conducting these types of projects are often very high.

2. Academic health centers invest in surer bets. Electing to invest start-up research dollars in individuals who conduct population-based clinical research as opposed to a basic scientist who has more opportunities to publish and obtain funding is an unappealing option for leaders of academic health centers who face overwhelm- ing incentives to recruit and retain investigators with multiple ROI grants.

And the number one obstacle to growing family medicine research is:

\section{Academia continues to question the value of pri- mary care services and, thus, primary care research.}

Virtually no primary care practice delivers all recommended care to every patient, every time, year after year. Research articles that report the shortfalls in primary care practice are more plentiful than those reporting primary care successes. ${ }^{12-16}$ Although a small body of high-profile research, such as the work of Barbara Starfield and the Commonwealth Fund, does demonstrate an association between the availability of primary care service and improved population health, finding quality gaps is much easier to do. Several studies and simulation models demonstrate that marked improvements in health outcomes can theoretically be achieved by bridging these gaps.

\section{The Value of Primary Care}

Despite the relatively large body of literature that demonstrates quality gaps in primary care practice, the actual value of providing primary care services is clear. Age-adjusted cancer mortality is declining for breast, cervix, lung, and colon cancers, each of which is amenable to prevention and early detection through screening or behavioral change. David Eddy and his team, using their Archimedes modeling method, have demonstrated that we have the potential to reduce cardiovascular morbidity and mortality by simply delivering primary care-based interventions that have been proven to work. ${ }^{17}$ Higher performing primary care practice has the potential to lead to a $63 \%$ reduction in myocardial infarctions and a $31 \%$ reduction in cerebrovascular accidents. Bridging just half of this quality gap would still have a profound effect on our nation's health. ${ }^{17}$ Developing systems to more consistently and effectively deliver primary care services is a highly appealing strategic goal for the nation.

Although skepticism about the value of primary care stubbornly persists, one central harsh reality is stoking the fires of change in our research enterprise. Our nations' health is unconscionably poor. International health care grading systems illustrate 


\begin{tabular}{lcccccc}
\hline & \multicolumn{5}{c}{ Cause of Mortality } \\
\cline { 2 - 4 } Country & Life Expectancy & Premature Mortality & Cancer & Circulatory Disease & Diabetes & Infant Mortality \\
\hline \multirow{2}{*}{ United States } & D & D & B & D & C & C \\
Japan & A & A & A & A & A & A \\
\hline
\end{tabular}

Adapted from reference 18.

the relative inadequacy of US health care (Table 1). Our "toxic environment" has led to an epidemic of overeating and sedentary living, and we are now the heaviest high-resource nation in the world. ${ }^{19}$ Tobacco use has largely plateaued, and chronic illness is rampant with numerous gaps in preventive care and chronic disease management. The bitter reality of our failure to effectively manage the health care enterprise has sewn the seeds of a research revolution.

\section{Components of the Research Revolution}

The research revolution has 3 components: the NIH roadmap, personalized medicine, and the creation of a new infrastructure funding mechanism for translational research:

1. The NIH roadmap was launched in September 2004. Intended to address perceived roadblocks to effective research, the roadmap was explicitly intended to transform the way research was conducted. Roadmap research programs were expected to have "exceptionally high potential to transform the manner in which biomedical research is conducted." ${ }^{20}$ Additional goals of the Roadmap are (1) faster, high-risk/high-reward research; (2) to enable the development of transformative tools and methodologies; (3) to fill fundamental knowledge gaps; and (4) to change academic culture to foster collaboration.

2. Personalized medicine is the use of genetic information to predict risk and therapeutic response. Determining personal risk based solely on a personal and family history will no longer be a clinical standard. Gene sequencing will be used in population health as well as basic science research.

3. The goal of the Clinical and Translational Science Awards is to "... help deliver improved medical care to the entire population, helping to disseminate new technologies and new advances in clinical practice." ${ }^{21}$

\section{The Research Revolution and Population Research}

The research revolution has created the opportunity for researchers who focus on the health of populations to become more engaged in the research enterprises of their academic health centers. As Steve Woolf ${ }^{22}$ wrote, "... patients might benefit more and more patients might benefit if the health care system performed better in delivering existing treatments than in producing new ones." The repercussions of this research direction shift the paradigm. Practice redesign, community participatory research, and projects that link the laboratory to the bedside to the office to the community become central to our nation's research portfolio. New partnerships between clinicians, public health professionals, community leaders, and both clinical and basic scientists are necessary to effectively fulfill this new research mandate. Institutions that are facile and visionary enough to create new multidisciplinary teams will receive funding and be able to conduct innovative work.

\section{Service Research}

One of the most important emerging research opportunities falls into a category that can be called "service research." Service research is based on collaborative efforts with communities, community service agencies, academic health centers, and government to design, implement, and evaluate programs that address an important health need. Much service research is translational, focusing on delivering proven interventions to socially complex, hard-to-reach individuals and populations.

Service research demands new design and evaluation methods. Multimethod approaches, both qualitative and quantitative, are needed. Sequential cluster analysis and other emerging approaches to 
testing interventions are often required. Funders for service research are diverse and include federal sources such as the Agency for Healthcare Research and Quality, the Centers for Disease Control and Prevention, and NIH, as well non-federal funders such as state government and not-forprofit community organizations and foundations. Many academic health centers need to learn a new language and approach to participate in this work. Frequently, the academic health center is not permitted to serve as the primary applicant. Often, the dollars available to support any one investigator or partner are smaller than those that are available through NIH grants; indirect payments are often less attractive, and all dollars often need to be shared with numerous collaborators from different participating organizations.

To compete effectively for service research dollars, academic health centers need to design new research infrastructures. Interdisciplinary centers and institutes that are prepared to provide service and participate in evaluation are important facilitators. Community partnerships are absolutely required and the commitment to meeting needs as perceived by the community is paramount. These centers or institutes often cannot be as diseasefocused as the research centers of the past; the unifying competency must be the ability to be a trusted community partner, to join in program implementation, and to use appropriate evaluative methods that fit the relative chaos of real life as opposed to the relative order of a basic or clinical science laboratory. Service research leads with true service but must extend to careful design and study.

\section{Marching Orders to Succeed in the Research Revolution Senior Researchers}

Senior, experienced researchers are our greatest asset in the research revolution, but the mantle of responsibility that they must bear is a heavy one. Senior researchers are expected to stay funded, mentor junior investigators, publish, advocate for primary care and public health research, and to find more reliable and sustaining funding mechanisms for family medicine research infrastructure. Relatively few individuals have been able to consistently address all of these needs, and the stress inherent in these roles is substantial. Finding ways to support our senior researchers is an important goal.

\section{Junior Investigators}

Junior investigators are our greatest hope in the research revolution. To be successful, junior investigators might be well served to follow the precepts below.

\section{Improving Health is What Matters}

Investigation that does not lead to dissemination through publications is not research and will not attract continued funding. The ultimate driver for a young researcher in the research revolution is the opportunity to answer important questions related to improving health; attracting the grants to support this work is the facilitating step, not the outcome.

\section{Be Prepared}

Family medicine residencies are far from adequate to provide the research skills and experiences necessary for a career researcher. The 1-year faculty development fellowship is rarely sufficient. Research fellowships are needed, and they must be long enough and have adequate focus to promote acquisition of research skills. Most successful family physician researchers acquire an additional degree such as a Master's or $\mathrm{PhD}$. These degrees are helpful, if not vital.

\section{Be Relentless}

Successful researchers have a need to know, a need to contribute to change. The road to independent $\mathrm{NIH}$ funding is a long one, requiring years of dedication and the resilience to accept disappointments. Junior investigators need to stay the course.

\section{Department Chairs}

Department chairs must be the chiefs of staff in the research revolution. With the passage of health reform, the substantial investment in the Agency for Healthcare Research and Quality and the Centers for Disease Control and Prevention, and the recognition of the vital role that primary care must play in a transformed health care delivery system, now is the moment to move research toward the top of departments' of family medicine agendas. The very specific roles that chairs and other senior academic leaders need to fill are below.

\section{Find and Engage Senior Mentors}

Research mentors who care about the health of populations reside in many different parts of our 
academic health centers and universities. Finding these individuals and securing their commitment to shared growth is a vital facilitating objective.

\section{Invest in Research}

Researchers-even seasoned career investigatorscan rarely completely cover the entire expense associated with their work. Department chairs face the difficult but crucial task of figuring out where to find the dollars to invest in research growth and support research gaps, particularly during tough funding periods. This demands creative, entrepreneurial action and the courage to take risks.

\section{Serve as Change Agents Within the Academic Health Center} Perhaps nothing will fuel the momentum of the research revolution more effectively than convincing academic health centers to embrace the mission to provide care to the populations living around them. Service research may demand an entirely new look at financial mechanisms and promotion policies. Research incentives need to be aligned to support collaboration. Coinvestigators need to be embraced, rewarded, and celebrated. The quickest route to these changes is to engage the senior leaders of the academic health center as fellow advocates in the research revolution, dedicated to population health, not just to receiving multiple ROI grants.

\section{The Prime Directive: Create a Culture of Scholarship}

Culture trumps intentions and wishes. Departments must create an environment that values inquiry, measurement, presentation, and publication. Creating departments that can play an important role in the research revolution will not happen passively. The goal must be integrated into the fabric of the department's work and be valued as equal to the missions of education and clinical care.

The research revolution will continue with or without departments of family medicine. We are not the only discipline that is passionately dedicated to improving population health. The NIH, the Agency for Healthcare Research and Quality, the Centers for Disease Control and Prevention, state governments, and foundations will not suffer from an inadequate number of grant applications. But family medicine departments enhance the work that can be performed. Family medicine is the bridge between community health, public health, and delivery of clinical care. The research revolution has begun, and opportunities to alter pro- foundly how we deliver care are being considered. Our discipline needs to be working hand in hand with communities, clinicians, public health providers, and researchers to help study and ultimately shape a more effective care delivery model.

\section{References}

1. Manton KG, Gu XL, Lowrimore G, Ullian A, Tolley HD. NIH funding trajectories and their correlations with US health dynamics from 1950 to 2004. Proc Natl Acad Sci U S A 2009;106:10981-6. Epub 22 Jun 2009.

2. American Cancer Society. Cancer Statistics 2009. Available at http://www.cancer.org/downloads/PRO/ Cancer_Statistic_2009_Slides_rev.ppt\#399,4,Change in US Death Rates* from 1991 to 2006. Accessed 1 June 2010.

3. Jemal A, Siegel R, Ward E, Hao Y, Xu J, Thun MJ. Cancer statistics, 2009. CA Cancer J Clin 2009;59:225-49.

4. Leaf C. Why we're losing the war on cancer and how to win it. Fortune Magazine, March 22, 2004.

5. Byers T, Barrera E, Fontham ET, et al. A midpoint assessment of the American Cancer Society challenge goal to halve the US cancer mortality rates between the years 1990 and 2015. CA Cancer J Clin 2006;107:396-405.

6. Blue Ridge Institute for Medical Research. Ranking tables of National Institutes of Health (NIH) Award Data 2006-2009. Available at http://brimr.org/ NIH_Awards/NIH_Awards.htm. Accessed 1 June 2010.

7. National Institutes of Health. NIH Research Portfolio Online Reporting Tools (RePORT). Available at http://report.nih.gov/award/trends/BrowseOrgs.cfm? NameBegins $=$ A\&InstFilter $=$ MS. Accessed 1 June 2010.

8. Seehusen DA, Weaver SP. Resident research in family medicine: where are we now? Fam Med 2009;41:663-8.

9. Rabinowitz HK, Becker JA, Gregory ND, Wender RC. NIH funding in family medicine: an analysis of 2003 awards. Ann Fam Med 2006;4:437-42.

10. NIH Office of Extramural Research and NIH FY 2007 Budget Summary. Available at http://opa1.faseb.org/ pdf/NIHFundingTrends.pps\#266,3,NIH Budget: FY1995 - 2007. Accessed 1 June 2010.

11. Lucan S, Barg F, Bazemore A, Phillips R. Family medicine, the NIH, and the medical-research roadmap: Perspectives from inside the NIH. Fam Med 2009;41:188-96.

12. Linder JA, Chan JC, Bates DW. Evaluation and treatment of pharyngitis in primary care practice: the difference between guidelines is largely academic. Arch Intern Med 2006;166:1374-9.

13. Linder JA, Nieva HR, Blumentals WA. Antiviral and antibiotic prescribing for influenza in primary care. J Gen Intern Med 2009;24:504-10.

14. Ma J, Urizar GG, Alehegn T, Stafford RS. Diet and 
physical activity counseling during ambulatory care visits in the United States. Prev Med 2004;39:815-22.

15. Scott JG, Cohen D, DiCicco-Bloom B, et al. Speaking of weight: how patients and primary care clinicians initiate weight loss counseling. Prev Med 2004; 38:819-27.

16. Mitchell AJ, Vaze A, Rao S. Clinical diagnosis of depression in primary care: a meta-analysis. Lancet 2009;374:609-19.

17. Kahn R, Robertson RM, Smith R, Eddy D. The impact of prevention on reducing the burden of cardiovascular disease. Circulation 2008;118:576-85.

18. The Conference Board of Canada, 2010. Report card. Available at http://www.conferenceboard.ca/ hcp/details/Health/life-expectancy.aspx. Accessed 1 June 2010.

19. Brownell KD. Does a "toxic" environment make obesity inevitable? Obes Manag 2005;1:52-5.

20. National Institutes of Health, United States Department of Health and Human Services. NIH common fund. Available at http://nihroadmap.nih.gov/. Accessed 25 May 2010.

21. Zerhouni EA. Translational research: moving discovery to practice. Clin Pharmacol Ther 2007;81:126-8.

22. Woolf SH. The meaning of translational research and why it matters. JAMA 2008;299:211-3. 